\title{
Orchids in Scotland: changes in their occurrence since 1950
}

\author{
David Trudgill \\ Newmill, Blairgowrie, Scotland
}

\section{Corresponding author: davetrudgill@googlemail.com}

This pdf constitutes the Version of Record published on $28^{\text {th }}$ February 2022

\begin{abstract}
The numbers of tetrad records (plus hectads without any tetrad records) in the BSBI Distribution Database collected annually for twenty species of orchids in Scotland increased 5.9-fold between the periods 1950-69 and 2010-2019. Similarly, the total numbers of records for all plant taxa (duplicates removed) also increased, but even more so (13.6-fold between 1950-69 and 2010-19). These increases were progressive and are thought to reflect an increase in the intensity of recording. Support for this suggestion was provided by regressing mean annual numbers of orchid tetrad records for five time periods since 1950 against the corresponding records for all plant taxa. This revealed that the increases in both were highly correlated $\left(R^{2}=0.99\right)$. To nullify the effect of the increase in recording effort on numbers of orchid tetrad records I used the corresponding total number of records for all plant taxa as a proxy for changes in amounts of recording. When this was done, compared to 1970-86, two-thirds of the orchid species had declined by more than $50 \%$ and two by $80 \%$ or more. One species had apparently increased.
\end{abstract}

Keywords: Orchids; Scotland; BSBI database; decline; recording.

\section{Introduction}

There is a widespread perception that most, or all of British orchid species are declining, but the published data are less clear-cut. A major source of data is the New Atlas of the British and Irish Flora (Preston et al., 2002). This provides data on the distribution of all vascular plants in the British Isles collected by the Botanical Society of Britain and Ireland (BSBI). Based on findings in Preston et al. (2002), Harrap \& Harrap (2009) reported that in the period 1970-86 the distributions of all British orchid species had declined (except for Ophrys fuciflora that is conserved at protected sites). Kull and Hutchings (2006), again based on the New Atlas, came to a similar conclusion, but their analysis is misleading as they included the numbers of records for 1987-99 in both sides of their calculations. Consequently, as species could only decline; the possibility of increase was excluded.

In reality, the data in the New Atlas are not as clear-cut as either of the above reports have claimed. In Preston et al. (2002), changes in the numbers of hectads (an area $10 \mathrm{~km} \times 10 \mathrm{~km}$ ) where each plant taxa was recorded in 1987-99 and 193069 were compared with those of an 'average species'. When this was done, 28 of 39 orchid species had a negative index (and had indubitably declined in hectad 
occupancy), but eleven species had a positive index and the change in their status was less certain.

Other recent studies also seem to present conflicting results. In 2003-4, as part of BSBI's 'Local Change' project, Braithwaite et al. (2006) re-surveyed 635 tetrads (an area $2 \mathrm{~km} \times 2 \mathrm{~km}$ ) that had been previously surveyed in 1987-88. They observed that seven of fourteen orchid species found in the original survey had increased between 1987-88 and 2003-04. Although these seven species had been collectively 'lost' from 106 tetrads they had been gained by a further 215 tetrads. In contrast, Walker et al. (2018) in their report on the results of BSBI's 'Threatened Plants Project' found no evidence of increases in orchid occurrence. Their report was based on 1,993 randomly selected 'historic' populations of 50 threatened species that included eight species of orchids. When these historic populations were revisited between 2008 and 2013 , on average, only $49 \%$ (range $61 \%$ to $31 \%$ ) of the orchid records were re-found.

I have used the BSBI Distribution Database (https://database.bsbi.org/) to explore changes in the occurrence of 20 species of orchids in Scotland between 1950 and 2019. The database contains more than 50 million records, stretching back nearly 100 years, for the occurrence and distribution of all plant taxa (species, closely related aggregates of species and interspecific hybrids) in the British Isles. The data are accumulated into a series of recording periods or date-classes that vary in length from 10 to 30 or more years. However, interpretation of trends and changes in species occurrence over time is confounded by a progressive increase in the intensity of recording (Amphlett, 2015). This is reflected in an increase in the total numbers of records collected for all plant taxa. To take account of this increase in recording, in this article I have expressed the numbers of orchid tetrad records as a proportion of the corresponding records for the total numbers of all plant taxa.

\section{Materials and Methods}

The number of tetrads for each of the 20 species of orchids (the currently recognized three species of Gymnadenia were treated as one species) recorded from Scotland and included in the BSBI database was determined. Because some of the earlier records were only for hectads, these have been added to the tetrad total provided there were no tetrad records within that hectad. Database records were accessed for the five, consecutive periods of recording viz. 1950-69, 1970-86, 198799, 2000-09 and 2010-19. Because these periods differ in length, the annual means were calculated for each species and recording period, and these are the values that have been used. The total numbers of records (duplicates removed) for all plant taxa in Scotland, for the same time periods, also came from the BSBI database and were supplied by Andy Amphlett. Again, annual means were calculated.

\section{Results}

The annual total of tetrad records for all twenty species of orchids progressively increased between 1950 and 2019 (Table 1). The equivalent numbers of records for all plant taxa also increased, but the increase was proportionally much greater than that for the orchids i.e. a 13.6-fold increase compared with 5.9-fold increase for orchids (Table 1). As a consequence, the number of orchid records as a percentage of those for all taxa progressively declined from $1.17 \%$ to $0.51 \%$ between $1950-69$ and 2010-19. 
Table 1. Total numbers of tetrad records collected for twenty species of orchids in Scotland, corresponding total records for all plant taxa, and orchid tetrad records as percentage of records for all taxa. Results are annual means for five time periods.

\begin{tabular}{|l|c|c|c|c|c|c|}
\hline & $\begin{array}{l}\mathbf{1 9 5 0} \\
\mathbf{6 9}\end{array}$ & $\begin{array}{l}\mathbf{1 9 7 0} \\
\mathbf{8 6}\end{array}$ & $\begin{array}{l}\mathbf{1 9 8 7 -} \\
\mathbf{9 9}\end{array}$ & $\begin{array}{l}\text { 2000- } \\
\mathbf{0 9}\end{array}$ & $\begin{array}{l}\text { 2010- } \\
\mathbf{1 9}\end{array}$ & $\begin{array}{l}\text { \% } \\
\text { Change }^{\mathbf{1}}\end{array}$ \\
\hline Orchids & 241 & 257 & 654 & 766 & 1430 & 5.9 \\
\hline All taxa & 20,617 & 31,343 & 105,216 & 134,436 & 280,696 & 13.6 \\
\hline \% Orchids & & & & & & 0.44 \\
& 1.17 & 0.82 & 0.62 & 0.57 & 0.51 & \\
\hline
\end{tabular}

${ }^{1}$ Between the first and last time periods

To determine whether these increases were correlated, the mean numbers of orchid tetrad records for the five recording periods were regressed against the corresponding total numbers of records for all taxa. When this was done, the increases in both were found to be strongly correlated $(P<0.001)$ and a linear regression accounted for almost all of the variation $\left(R^{2}=0.997\right)$. Consequently,

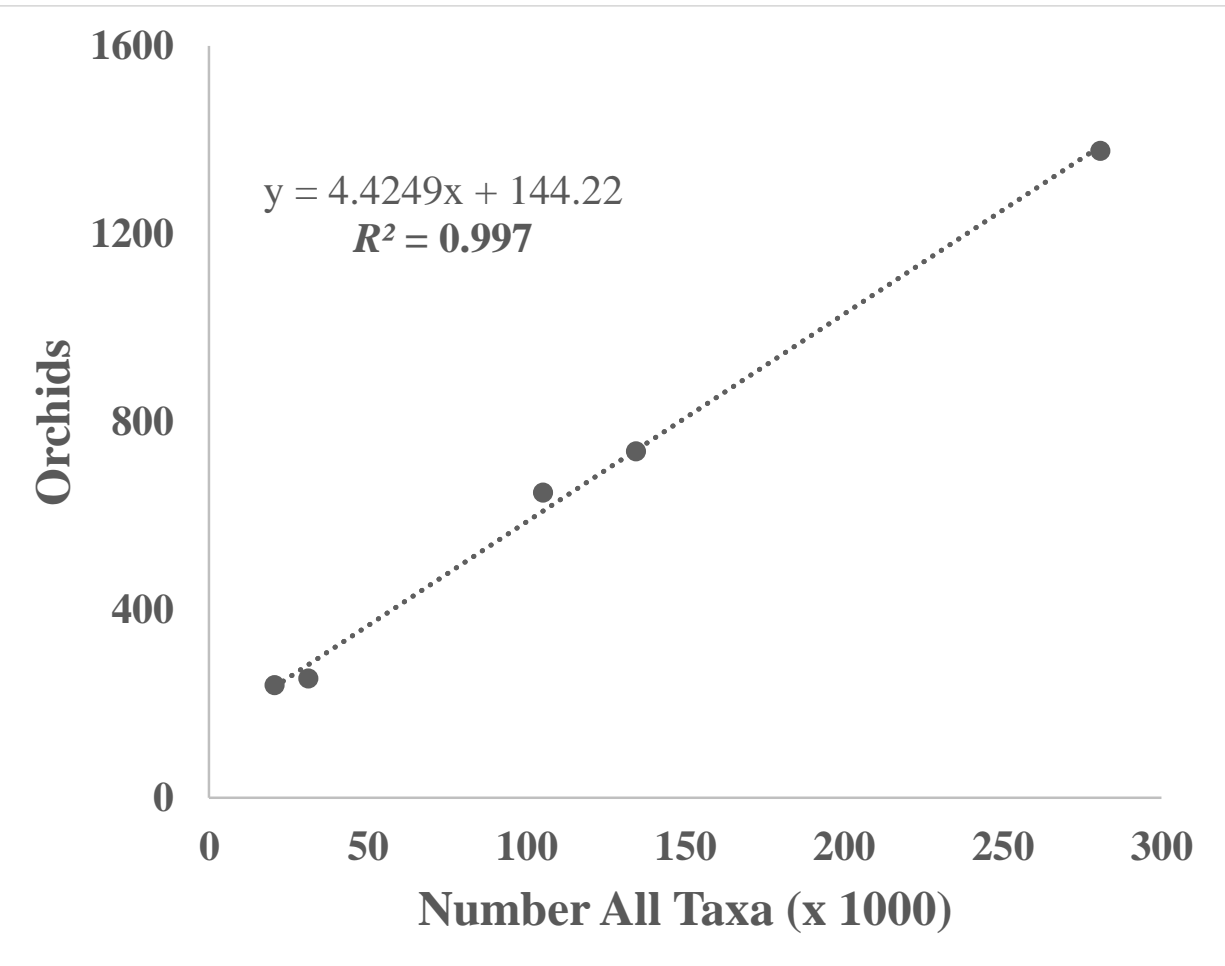

Figure 1. Annual numbers of tetrad records for twenty species of orchids collected during five time periods regressed against corresponding total number of records for all plant taxa. 
it seems likely that the increases in both are being driven largely by the same factor (i.e. increased recording), and that expressing the numbers of orchid tetrad records as a percentage of the total records for all taxa is a potentially effective means of revealing the underlying changes in orchid tetrad numbers.

The remainder of this article focuses on the changes in the occurrence of individual species of orchid between 1970-86 and 2010-19. All species increased when the annual mean numbers of orchid tetrad records for 2010-19 are compared with those for $1970-86$, many by 5 -fold or more (Table 2). However, when the tetrad records for the orchids were expressed as a percentage of the numbers of records for all taxa (hereafter ' $\%$ orchids') all species decreased except for Dactylorhiza maculata.

Table 2. Mean annual numbers of tetrad records for each of $\mathbf{2 0}$ species of orchids in 1970-86 and 2010-19, and the same values expressed as a percentage of corresponding total numbers of records for all taxa. The species are arranged in two groups depending on whether the percentage change in orchid tetrad records as a percentage of all taxa between 1970-86 and 2010-19 (i.e. final column) was less than or exceeded $66 \%$

\begin{tabular}{|c|c|c|c|c|c|}
\hline & \multicolumn{2}{|c|}{ Number/year } & \multicolumn{2}{|c|}{$\%$ of all taxa } & \multirow{2}{*}{$\begin{array}{c}\% \\
\text { decrease }\end{array}$} \\
\hline & $1970-86$ & 2010-19 & $1970-86$ & 2010-19 & \\
\hline \multicolumn{6}{|l|}{$\begin{array}{l}\text { Group } 1 \text { (decreased by } \\
<66 \% \text { ) }\end{array}$} \\
\hline Anacamptis pyramidalis & 0.9 & 6.1 & 0.0028 & 0.0022 & -21 \\
\hline Dactylorhiza fuchsii & 31.1 & 166.7 & 0.0992 & 0.0594 & -40 \\
\hline D. incarnata & 13.6 & 60.6 & 0.0436 & 0.0216 & -50 \\
\hline D. maculata & 43.6 & 456.2 & 0.1395 & 0.1636 & +7 \\
\hline D. purpurella & 30.2 & 214.6 & 0.0966 & 0.0765 & -21 \\
\hline Epipactis helleborine & 5.4 & 30.6 & 0.0173 & 0.0109 & -37 \\
\hline Goodyera repens & 5.4 & 46.3 & 0.0168 & 0.0165 & -2 \\
\hline Gymnadenia spp. & 21.2 & 80.8 & 0.0670 & 0.0288 & -57 \\
\hline Neottia cordata & 19.3 & 117.0 & 0.0617 & 0.0417 & -32 \\
\hline N. ovata & 14.4 & 44.9 & 0.0459 & 0.0160 & -65 \\
\hline Platanthera bifolia & 13.7 & 39.7 & 0.0336 & 0.0142 & -58 \\
\hline P. chlorantha & 10.9 & 32.6 & 0.0316 & 0.0116 & -63 \\
\hline Means & 17.5 & 108.0 & 0.0546 & 0.0386 & \\
\hline \multicolumn{6}{|l|}{$\begin{array}{l}\text { Group } 2 \text { (decreased by } \\
>66 \% \text { ) }\end{array}$} \\
\hline Cephalanthera longifolia & 0.8 & 3.7 & 0.0055 & 0.0013 & -76 \\
\hline Corallorhiza trifida & 4.1 & 7.5 & 0.0131 & 0.0027 & -79 \\
\hline Dactylorhiza viridis & 11.5 & 34.0 & 0.0353 & 0.0121 & -66 \\
\hline Hammarbya paludosa & 4.0 & 11.5 & 0.0132 & 0.0041 & -69 \\
\hline Neottia nidus-avis & 3.0 & 9.5 & 0.0128 & 0.0034 & -73 \\
\hline Orchis mascula & 18.4 & 52.7 & 0.0580 & 0.0188 & -68 \\
\hline Epipactis atro-rubens & 0.8 & 1.7 & 0.0036 & 0.0006 & -83 \\
\hline Pseudorchis albida & 7.4 & 13.0 & 0.0229 & 0.0046 & -80 \\
\hline Means & 6.3 & 16.7 & 0.0206 & 0.0060 & \\
\hline
\end{tabular}


A comparison of the two groups of species in Table 2 suggests that there was a tendency for those species that were less widespread to have proportionally decreased the most (i.e. the rarer a species, the greater the likely decline in occupancy). Anacamptis pyramidalis and Goodyera repens were notable exceptions to this tendency. Epipactis atro-rubens and Pseudorchis albida apparently had decreased the most (>80\%). Of the five Dactylorhiza species, only $D$. viridis decreased by $>50 \%$.

Regressing the percentage decrease between 1970-86 and 2010-19 (see Table 2, last column) against mean tetrad numbers for 2010-19 (see Table 2, second data column) supported the suggestion that, based on the tetrad records, the less abundant a species was in both 1970-86 and 2010-19 the greater the percentage decline. A linear regression (Fig.2) accounted for $52 \%$ of the variation and the correlation was significant $(P=0.01)$.

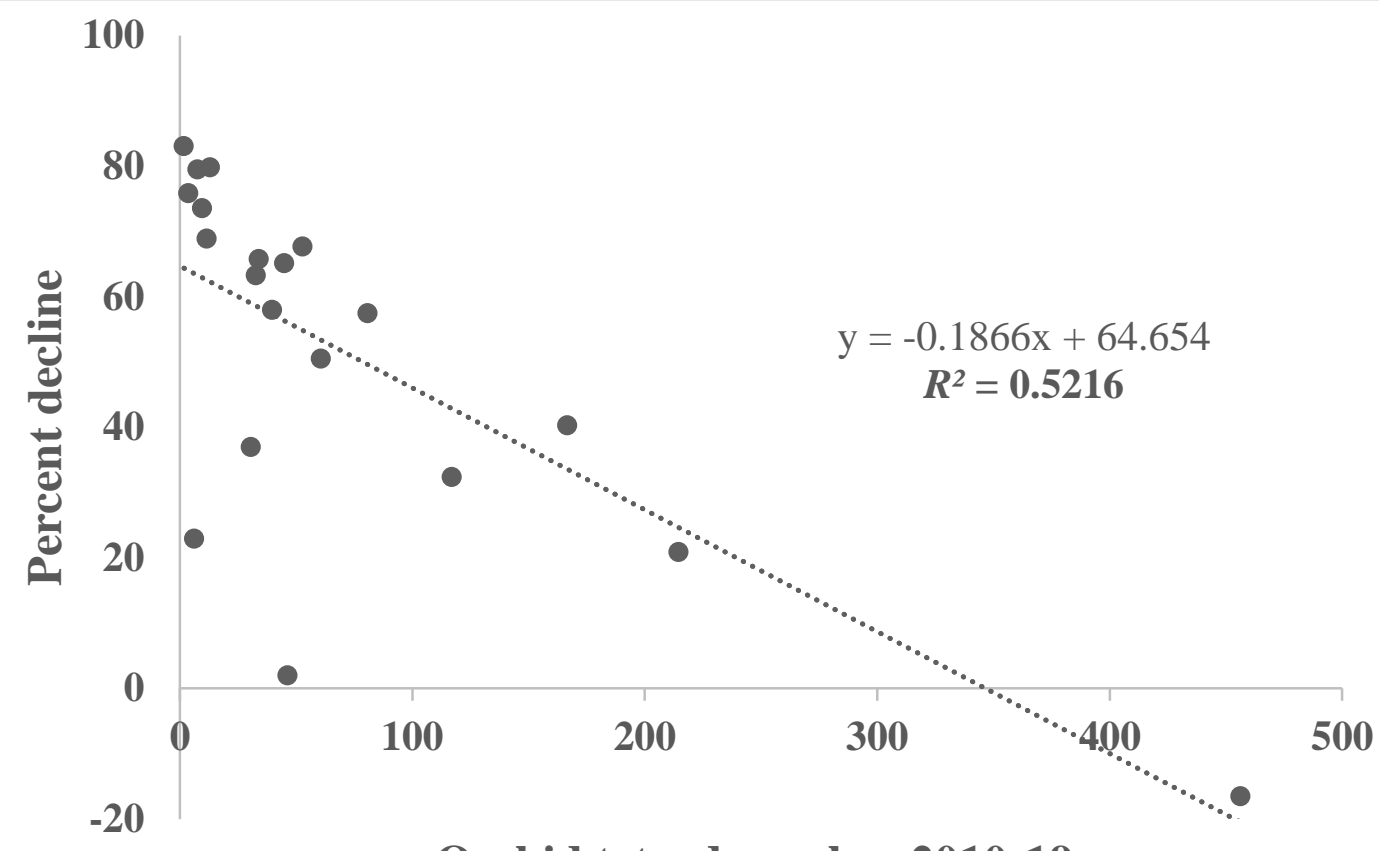

Orchid tetrad number 2010-19

Figure 2. Numbers of tetrad records for each orchid in 2010-19 and percentage decrease from 1950-69 when expressed as proportion of all taxa.

To better visualise and compare overall rates of decline since 1950-69 the mean percentage orchid records for the five time periods were firstly expressed as a percentage of the 1950-69 value and then regressed against time (in years) since 1969 (Fig. 3). A negative exponential regression accounted for $97 \%\left(R^{2}=0.97\right)$ of the variation. A linear regression fitted to the same data accounted for $93 \%$ of the variation and extrapolation of the linear regression to the $x$ axis indicated that no orchids would be recorded after 2052. This prediction is clearly unrealistic, but it does indicate that there is little room for complacency regarding the long-term future, especially for some of Scotland's orchids. This is because the values in Fig. 3 are the average rates of decline for 20 species and, as shown in Table 2, some 
species are declining more rapidly than others e.g. Pseudorchis albida (Small-white Orchid) has steadily declined in occupancy by $c .34 \%$ for each decade between 1950 69 and 2010-19.

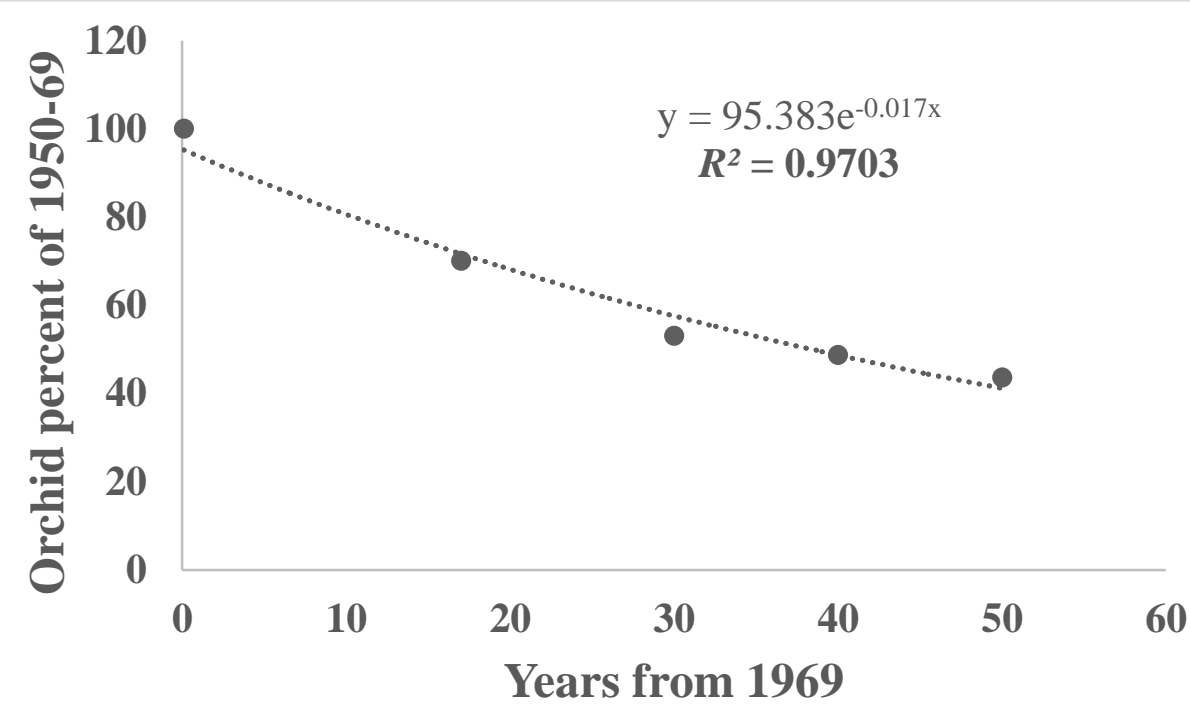

Figure 3. Decline in orchid records (as percentage of all taxa) regressed against number of years from 1969. A negative exponential regression was fitted to the data.

\section{Discussion}

Interpretation of the changes over time in the numbers of records for species in the BSBI database is bedevilled by changes in the intensity of recording. Based on the strong correlation between numbers of orchid tetrad records and the total numbers of records for all taxa, I have used the latter as a proxy for these changes in recording intensity and as a means of adjusting the numbers of orchid records. Whilst this appears to be an effective and revealing approach, it is necessary to be aware that the total numbers of records for all taxa is based on the whole of Scotland, and therefore its use is most appropriate for orchids with national rather than regional distributions. Other changes in recording have occurred between 1950 and 2019. In particular there has been a $28 \%$ increase across the British Isles in the numbers of taxa recorded in the BSBI database. In 1970-86 a total of 5009 taxa were recognised in the database. This had increased to 5444 in 2000-09, and to 6395 in 2020-19 (A. Amphlett, pers. comm.). This increase is probably mostly due to an increase in the recording of alien taxa and, consequently, the numbers of records involved are likely to be relatively small, especially in Scotland. The apparent increase in $D$. maculata (Table 2) may reflect another form of bias and result from a change in the balance of recording between the highlands and the lowlands.

Despite the foregoing qualifications, the values in Table 2 provide the best estimate currently available for the rates of decline in occupancy of these twenty orchid species in Scotland over the previous 50 years. However, they do not provide a complete picture of all the changes since 1970-86. The orchid data used here is for tetrads (plus appropriate hectads) where each orchid species had been recorded. The numbers of populations of each species in each tetrad, and their size are not given. Consequently, populations could have been lost from a tetrad, or could have 
diminished numerically, without any change in that tetrad's positive status for that species - provided at least one plant remained (and was recorded). And, when a species is in decline, it seems almost certain that these losses will exceed gains. The rate at which orchids are decreasing may be slowing (Fig. 3) and, because there is a margin of error in the percentage calculations, it is possible that some species of orchids with restricted distributions and a low rate of decline, such as $A$. pyramidalis, are really increasing rather than declining. Anacamptis pyramidalis is mostly found on the islands on the west coast of Scotland where it appears to be extending its range northwards (Trudgill, 2018). It is rarer in eastern Scotland, and there it has slightly declined. One species, Ophrys apifera (Bee Orchid), is undoubtedly increasing but was not included in this study because it was not recorded in Scotland before 2000 . Since then it has increased and spread northwards, probably aided by our warming climate (Trudgill, 2018).

The decline in the numbers of orchid records as a percentage of all taxa was less in Scotland than that in some other parts of the British Isles. A study of 18 species of orchids (all of which are included in the current study, with the addition of Corallorhiza trifida and Goodyera repens) native to all four regions of the British Isles found that these orchids were, in total, more abundant in Scotland (Table 3), and had declined less than in England and Wales (Trudgill, 2022). The records for Ireland were similar to those for Scotland.

Table 3. Numbers of records for 18 species of orchid as percentage of corresponding records for all taxa for five time periods in four different regions of the British Isles.

\begin{tabular}{|l|l|l|l|l|l|}
\hline & England & Wales & Scotland & Ireland & Mean \\
\hline \multicolumn{6}{|c|}{ \% all taxa } \\
\hline $1950-69$ & 0.58 & 0.83 & 1.16 & 1.03 & 0.90 \\
\hline $1970-86$ & 0.44 & 0.70 & 0.81 & 0.89 & 0.71 \\
\hline $1987-99$ & 0.28 & 0.43 & 0.62 & 0.56 & 0.47 \\
\hline $2000-09$ & 0.23 & 0.26 & 0.53 & 0.58 & 0.41 \\
\hline $2010-19$ & 0.17 & 0.20 & 0.49 & 0.38 & 0.31 \\
\hline Mean & $\mathbf{0 . 3 3}$ & $\mathbf{0 . 4 8}$ & 0.72 & 0.69 & \\
\hline \% Decline & $\mathbf{7 1 \%}$ & $\mathbf{7 6 \%}$ & $\mathbf{5 8 \%}$ & $\mathbf{6 3 \%}$ & \\
\hline
\end{tabular}

${ }^{1}$ From the first to last time period

Using the numbers of records for all taxa as a proxy for changes in the intensity of recording, is simplistic. It lacks the analytical power of complex programs such as the 'Frescalo' local occupancy model (Pescott et al., 2019), but it is likely to be more readily accessible and understood. Also, as discussed, it makes assumptions about 
the consistency of the recording over time and can be subject to biases. In particular, orchids are an iconic group and a greater proportion of populations, especially of rarer species, may have been identified than indicated by the numbers of records for all taxa. Consequently, the conclusion, based on Figure 2, that the rate of decline of less abundant species is greater than that of those that are more abundant may need to be viewed with caution. Even so, the differences between species and the consistency of the trends are persuasive that, overall, the results are meaningful and provide a realistic assessment of past changes in orchid distributions and the future threat to many orchid species.

\section{Acknowledgements}

I thank Andy Amphlett for help with extracting summary data from the BSBI database, and Liz and Alistair Lavery for helpful comments and data analysis.

\section{References}

Amphlett. A. 2015. Recording precision 1950 - 2014. BSBI News 129: 75-81.

Braithwaite, M.E., Ellis, R.W. \& Preston, C.D. 2006. Change in the British flora 1987 2004. London: Botanical Society of the British Isles.

Harrap, A. \& Harrap, S. 2009. Orchids of Britain and Ireland, a field and site guide. London: A. \& C. Black.

Kull, T. \& Hutchings, M.J. 2006. A comparative analysis of decline in the distribution ranges of orchid species in Estonia and the United Kingdom. Biological Conservation 129: 31-39. https://pubpeer.com/publications/58B16F03A1C6494A50B80BAEB68589

Preston, C.D., Pearman, D.A. \& Dines, T.D. 2002. New Atlas of the British and Irish Flora. Oxford: Oxford University Press.

Pescott, O.L., Humphrey, T.A., Stroh, P.A. \& Walker, K.J. 2019. Temporal changes in distributions and species atlas: How can British and Irish plant data shoulder the inferential burden? British and Irish Botany 1(4): 250-282.

Trudgill, D. 2018. Impact of climate change on potential Ophrys apifera distribution. Journal of the Hardy Orchid Society 16 (1): 32-35.

Trudgill, D. 2022. An exploration of orchid records in the BSBI database in four regions of the British Isles over five periods of time. BSBI News 149: 16-22.

Walker. K, Stroh. P, \& Ellis, B. 2018. Why are some plant species more threatened than others? Evidence from the BSBI's Threatened Plants Project. BSBI News 137: 3-9.

Copyright retained by author(s). Published by BSBI under the terms of the Creative Commons Attribution 4.0 International Public License.

ISSN: $2632-4970$

https://doi.org/10.33928/bib.2022.04.034 